\title{
Percutaneous Transluminal Mitral Commisuriotomy for Mitral Stenosis in Shahid Gangalal National Heart Centre, Kathmandu, Nepal
}

\author{
Chandra Mani Adhikari
}

Department of Cardiology, Shahid Gangalal National Heart Centre, Bansbari, Kathmandu, Nepal Corresponding Author: Chandra Mani Adhikari, Shahid Gangalal National Heart Centre, Bansbari,Kathmandu, Nepal Email:topjhap@hotmail.com

\begin{abstract}
Mitral stenosis (MS) is almost invariably the result of long term complication of rheumatic fever. Based upon the nature and severity of MS, patients can be managed with medical treatment, percutaneous transvenous mitral commissurotomy (PTMC) or surgery. PTMC is proven to be simple, effective and safe; it is considered as treatment of choice in the management of MS. In Shahid Gangalal National Heart Centre, PTMC service started in 2001. First PTMC in the centre was done on 14th April 2001. Till June2016, 6023 PTMCs were done in the centre. Multiple studies evaluated the safety and efficacy of PTMC in different groups of patients. These studies clearly demonstrated the safety and effectiveness of PTMC in our centre. This article summarizes the historical development, current status and future perspectives of PTMC procedure at Shahid Gangalal National Heart Centre, a teritary care cardiac centre in Nepal.
\end{abstract}

\section{Introduction}

Acquired Mitral stenosis (MS) is almost invariably the result of long term sequelae of rheumatic fever. ${ }^{1}$ Approximately $25 \%$ of patients with rheumatic heart disease (RHD) have isolated MS, and an additional $40 \%$ have combined MS and mitral regurgitation (MR). ${ }^{2,3}$

Based upon the nature and severity of MS, patients can be managed with medical therapy, percutaneous transluminal mitral commissurotomy (PTMC) or surgery. Since 1984, PTMC has revolutionized the treatment of patients with symptomatic MS. ${ }^{4}$ Patients with favorable morphology have procedural success rate of more than $90 \%$ whereas procedural mortality nowadays is less than one percent. Urgent surgery for severe MR during PTMC is rarely required. ${ }^{5}$ Nearly half of all patients who undergo PTMC remain free from cardiovascular death or surgery at 20 years, only $25 \%$ of them need repeat procedure. ${ }^{6}$ PTMC can be repeated for those who develop restenosis if mitral valve is still suitable for it. PTMC clinical applications have been widely accepted and a large series has been reported. ${ }^{7}$ It was proven that, it is as effective as open valvotomy and more effective than closed valvotomy. ${ }^{8,9,10}$ As there are very few contraindications for the procedure, so it has greatly decreased the need for surgery. ${ }^{11}$ It has established itself as the procedure of choice for symptomatic MS patients.

PTMC is recommended for symptomatic patients with severe MS (mitral valve area (MVA) $\leq 1.5 \mathrm{~cm}^{2}$ ) and favorable valve morphology in the absence of left atrial (LA) thrombus and or moderate-to-severe MR. ${ }^{12}$ In this article experience of PTMC in Shahid Gangalal National Heart Centre (SGNHC), Bansbari, Kathmandu, Nepal is reviewed.

\section{Overview of PTMC at SGNHC}

To serve the Nepalese patients with MS, PTMC service started in SGNHC in $2001 .{ }^{13}$ First PTMC in the centre was done on 14th April 2001. Till June2016, 6023 PTMCs were done in SGNHC. Government of Nepal provides free PTMC services to all the patients. This service is beneficial for poor patients.

During these years, few studies on safety and efficacy of PTMC in different subgroups were published. In the first study published to evaluate the safety and efficacy of PTMC in SGNHC, Two hundred patients from January 2003 to July 2004 were studied. Seventy four percent of the patients were female. Age ranged from 10 years to 61 years with the mean age 29 years. Atrial fibrillation (AF) was present in $32 \%$ of the cases. Mean MVA increased from $0.9 \pm 0.1 \mathrm{~cm}^{2}$ to $1.8 \pm 0.2 \mathrm{~cm}^{2}$. Mean LA pressure decreased from 21 to $7 \mathrm{mmHg}$. There was no mortality during the hospital stay or within the first month of the procedure. Two patients developed severe MR. ${ }^{14}$

One thousand and one patients from March 2003 to March 2008 were studied. Seventy eight percent of the patients were female. Age ranged from 9 years to 68 years with mean age $31.2 \pm 12.4$ years. MVA increased from $0.88 \pm 0.1 \mathrm{~cm}^{2}$ to $1.67 \pm 0.2 \mathrm{~cm}^{2} . \mathrm{LA}$ pressure decrease from $29.7 \pm 8.6$ to $12.8 \pm 5.3$ $\mathrm{mmHg}$. Severe MR was noted in $2.1 \%$ patients. One had to undergo urgent mitral valve replacement (MVR) due to severe MR, two died of pulmonary edema due to severe MR. There were three deaths due to cardiac tamponade and one death in pregnant women who died due to abortion and subsequent septicemia. ${ }^{15}$ 
In a recent prospective ${ }^{16}$ study where Successful PTMC was defined as mean LA pressure decrease by $>50 \%$ as compared to the baseline, MVA increase by $>50 \%$ as compared to the baseline and final absolute MVA of $>1.5 \mathrm{~cm}^{2}$ in the absence of more than moderate MR;. all the 262 patients who underwent PTMC during July 2013 to June 2014 were included in the study, Seventy four percent of the patients were female. Age ranged from 10 to 76 years with mean age of $33.2 \pm 12.5$ years. $\mathrm{AF}$ was present in $26.7 \%$ patients; $2 \%$ patients were pregnant; $4.6 \%$ patients previously underwent surgical or balloon commissurotomy. LA size ranged from $3.3 \mathrm{~cm}$ to $7.9 \mathrm{~cm}$ with the mean of $4.97 \pm 0.76 \mathrm{~cm}$. The procedural success was achieved in $84 \%$ patients. Mean LA pressure decreased from $26.8 \pm$ $8.9 \mathrm{mmHg}$ to $15.6 \pm 7.2 \mathrm{mmHg}$. MVA increased from $0.9 \pm 0.17$ $\mathrm{cm}^{2}$ to $1.6 \pm 0.28 \mathrm{~cm}^{2}$.Moderate to severe MR was seen in $49(18.7 \%)$ patients after PTMC but none of them required emergency MVR. There was no mortality related to the procedure.

\section{PTMC in elderly}

In a retrospective study in elderly ${ }^{17}$ patients, 49 patients aged 60 years and above underwent PTMC between March 2007 to March 2013. It accounts less than $2 \%$ of the total PTMC done during the study period. Successful PTMC was defined as increase in MVA $>1.5$ $\mathrm{cm}^{2}$ without more than moderate MR. Female to male ratio was 3.4:1, Patient age ranged from 60 to 77 years with the mean age of $64.5 \pm 4.0$ years. $\mathrm{AF}$ was present in $61.3 \%$ patients. LA size range from 3.6 to $8.8 \mathrm{~cm}$ with the mean of $5.5 \pm 1.2 \mathrm{~cm}$. The MVA increased from $0.9 \pm 0.1$ to $1.6 \pm 0.3 \mathrm{~cm}^{2}$ following PTMC. Mean LA pressure decreased from $25.4 \pm 6.6$ to $12.9 \pm 4.5 \mathrm{mmHg}$. Severe MR occurred in one patient. Successful results were observed in $83.6 \%$ patients. There were no other complications like death, pericardial effusion.

\section{PTMC in children}

In a retrospective study was performed from November 2009 to May 2013 to evaluate the safety and efficacy of PTMC in children. ${ }^{18}$ During the study period total 2237 PTMC were done, among them 100 patients aged less than 15 years underwent PTMC procedure for severe MS. Successful PTMC was defined as increase in MVA by $50 \%$ or more, or MVA more than $1.5 \mathrm{~cm}^{2}$ and decrease in mean LA pressure to $18 \mathrm{mmHg}$ or less without significant $\mathrm{MR}$ or any other complications. The mean age was $13 \pm 1$.6 years and $48 \%$ were male. The mean LA size was $4.4 \pm 0.6 \mathrm{~cm}$. After PTMC, MVA increased from $0.7 \pm 0.1 \mathrm{~cm}^{2}$ to $1.5 \pm 0.3 \mathrm{~cm}^{2}$ and mean LA pressure decreased from $29 \pm 7.9 \mathrm{mmHg}$ to $13.9 \pm 6.2 \mathrm{mmHg}$. Success rate of PTMC was $94 \%$.

\section{PTMC in Juvenile Patients (younger than 20 years of age)}

In a retrospective study of PTMC in 131 juvenile patients who underwent elective PTMC ${ }^{19}$ from July 2013 to June 2015 were studied. Patients with symptomatic MS and MVA less than $1.5 \mathrm{~cm}^{2}$ with favorable mitral valve morphology were included. Among the 131 patients $53.4 \%$ were female and $\mathrm{AF}$ was present in $16(12.3 \%)$ patients. LA size ranged from 2.9 to $6.1 \mathrm{~cm}$ with the mean of $4.5 \pm 0.6$ $\mathrm{cm}$. The mean MVA increased from $0.8 \pm 0.1 \mathrm{~cm}^{2}$ to $1.6 \pm 0.2 \mathrm{~cm}^{2}$ following PTMC. Mean LA pressure decreased from $27.5 \pm 8.6$ to $14.1 \pm 5.8 \mathrm{mmHg}$. Post procedure severe MR was seen $3.8 \%$ patients. Among them one patient needed MVR after the PTMC, patient died after MVR. Successful PTMC was defined as increase in MVA to $>1.5 \mathrm{~cm}^{2}$ without more than moderate MR. Our success rate was $87.7 \%$.

\section{PTMC in pregnancy}

A study was done in twenty two pregnant women from Jan 2003 to Dec 2007 to evaluate the safety and efficacy of PTMC with severe MS. PTMC was done during the $24.2 \pm 4$.6 weeks of gestation. Mean age was $23 \pm 4.2$ years and two patients were in AF. Fluoscopy time needed to complete the procedure was $7.5 \pm 4.8 \mathrm{~min}$. Procedure was successful in all patients. Mean MVA increased from $0.7 \pm 0.2 \mathrm{~cm}^{2}$ to $1.8 \pm 0.2 \mathrm{~cm}^{2}$. Mean LA pressure decreased from $28.1 \pm 4.3 \mathrm{mmHg}$ to $15.3 \pm 6.2 \mathrm{mmHg}$. Twenty patient had a normal delivery whereas two underwent caesarean section. There was no maternal morbidity or mortality or intrauterine growth retardation.

\section{PTMC in special condition}

Expertise in the field of PTMC from our centre was well tested in a recent publication. ${ }^{20}$ Though LA appendage clot is contraindicated for PTMC. All cases of MS with significant dyspnea and MVA $<1.5 \mathrm{~cm}^{2}$ with LA appendage clot and a condition which preclude the patient to continue anticoagulation therapy and needed urgent intervention from January 2011 to December 2013 were included. Patients with LA body thrombus, LA appendage clot extending into Left atrium, mitral regurgitation with $>3$ grade, bicommissural calcification or severe calcification, and severe aortic valve disease were excluded. Age of the patients ranged from 20 years to 58 years with the Mean age of $31.4 \pm 9.3$ years. Male to female ratio was 0.35 . Twenty patients underwent PTMC despite LA appendage clot for different reasons. The successful PTMC was defined as the doubling of MVA from the initial area or achieving the MVA of $1.5 \mathrm{~cm}^{2}$ or drop of LA pressure to half the initial value. LA mean pressure decreased from 20 to $10 \mathrm{mmHg}$. Subjective improvement was reported in all 20 patients. All had fulfilled criteria for successful PTMC. There has been no mortality during hospital stay and in one-week follow-up. No one had any neurological complications or stroke. There was no need for emergency surgery in any of the cases.

Though there are multiple studies to evalute the safety and efficacy of PTMC in our patients, we still don't have any study about the long term effect of PTMC in our patients. We need a long term study to evaluate the safety and efficacy of this simple procedure in immediate future. However, difficulty in following up the patient remains a big hurdle.

\section{Conclusion}

Though the long term safety and efficacy is yet to be studied in our patient population, immediate results show that PTMC is proven to be safe and effective method of choice in the treatment of in Nepalese MS patients.

\section{References}

1. Olson LJ, Subramanian R, Ackermann DM - Surgical pathology of the mitral valve; a study of 712 cases spanning 21 years. Mayo clinics proc 1987; 62:22-7

2. Dare A. Evaluation of surgically excised mitral valves: Revised recommendations, based on changing operative procedures in the 1990s. Hum Pathol 1993; 24:1286.

3. Waller B, Howard J, Fess S. Pathology of mitral stenosis and pure mitral regurgitation-part I.Clin Cardiol 1994; 17:330.

4. Inoue K, Owaki T, Nakamura T, et al.- Clinical application of transvenous mitral commissurotomy by a new balloon catheter. J Thoracic Cardiovasc Surg 1984; 87:394-402

5. Clinical Cardiology current practice guidelines. Oxford university press.First edition 2013.

6. Bouleti C, Iung B, Himbert D, Brochet E, Messika-Zeitoun $\mathrm{D}$, Détaint $\mathrm{D}$, et al. Reinterventions after percutaneous mitral commissurotomy during long-term follow-up, up to 20 years: the role of repeat percutaneous mitral commissurotomy. Eur Heart J. 2013;34:1923-30.

7. Nobuyoshi M, Hamasaki N, Kimura T, et al. - Indication, complications, and short-term clinical outcome of 
percutaneous tranvenous mitral comissurotomy. Circulation 1989;80:782-92

8. Farhat MB, Ayari M, Maatouk F, et al.- Percutaneous balloon versus surgical closed and open mitral commissurotomy:sevenyear follow-up results of a randomized trial. Circulation 1998;97:245-250

9. Turi ZG, Reyes VP, Raju BS, et al.- Percutaneous balloon versus surgical closed commissurotomy for mitralstenosis.A prospective, randomized trial.Circulation 1991; 83:1179-1185

10. Reyes VP, Raju BS, Wynne J, et al.- Percutaneous balloon valvuloplasty compared with open surgical commissurotomy for mitral stenosis. N Engl JMed 1994; 331:961-967

11. Sule Korkmaz,Burcu Demirkan, Yesim Guray, et al. Long-Term Follow-Up of Iatrogenic Atrial Septal Defect after Percutaneous Mitral Balloon Valvuloplasty. Tex Heart Inst J 2011;38(5):523-7.

12. Rick A. Nishimura,Catherine M. Otto,Robert O. Bonow, et. al. 2014 ACC/ AHA Guideline for the management of patients with valvular heart disease, A report of the American college of Cardiology/American Heart Association Task force on Practice Guidelines.J Am Coll Cardiol. 2014;63(22):2438-2488.

13. Annual Report of Shahid Gnagalal National Heart Centre, 2002

14. Rajbhandari R, Man Bahadur KC, Bhatta Y. Percutaneous transvenous mitral commissurotomy. Nepal Med Col J. 2006;8:182-184.

15. Raiib Rajbhandari, Yadav Bhatta, Ravi Malla, et al. Percutaneous transvenous mitral commissurotomy,Shahid Gangalal National heart centre-Registry. 2009 Circulation
Journal2009;73(SupplI):396.

16. Nagma Shrestha, Yadav Kumar Dev Bhatta, Arun Maskey,et al. Immediate Outcome of Percutaneous Balloon Mitral Valvotomy in Shahid Gangalal National Heart Centre, Bansbari, Kathmandu, Nepal. Nepalese HeartJournal 2015; 12 (1): 11-14.

17. Chandra Mani Adhikari, R Malla, R Rajbhandari,et al.Percutaneous Transvenous Mitral Commissurotomy in elderly mitral stenosis patients.A retrospective study at Shahid Gangalal National Heart Centre , Bansbari, Kathmandu,Nepal.Maedica-a Journal of Clinical Medicine 2013;8(4)333-337.

18. Shrestha M, C M Adhikari, Shakya U, et al. Percutaneous Transluminal Mitral Commissurotomy in Nepalese children with Rheumatic Mitral Stenosis. Nepalese Heart Journal 2013;10(1):23-26.

19. Adhikari CM, Malla R, Rajbhandari R, et al. Percutaneous transvenous mitral commissurotomy in juvenile mitral stenosis. Cardiovasc Diagn Ther 2016;6(1):20-24.

20. Regmi SR, Maskey A, Dubey L, et al. Balloon Mitral Valvuloplasty (BMV) in pregnancy: A four year experience at Shahid Gangalal National Heart Centre (SGNHC), Nepal. Nepalese Heart J 2009;6:35-8.

21. Rajib Rajbhandari,RabiMalla,Arun Maskey,etal.Percutaneous transvenous mitral commissurotomy in mitral stenosis and left atrial appendage clot patients in special conditions: Hospitalbased study, Indian Heart J. (2016), http://dx.doi.org/10.1016/ j.ihj.2016.04.020
Cite this article as: Chandra Mani Adhikari. Percutaneous Transluminal Mitral Commisuriotomy for Mitral Stenosis in Shahid Gangalal National Heart Centre, Kathmandu, Nepal. Nepalese Heart Journal 2016;13(2): 15-17. 